\title{
Mistaking Randomness for Free Will
}

\section{Citation}

Ebert, Jeffrey P. and Daniel M. Wegner. 2011. Mistaking randomness for free will. Consciousness and Cognition 20(3): 965-71.

\section{Published Version}

doi:10.1016/j.concog.2010.12.012

\section{Permanent link}

http://nrs.harvard.edu/urn-3:HUL.InstRepos:9029778

\section{Terms of Use}

This article was downloaded from Harvard University's DASH repository, and is made available under the terms and conditions applicable to Open Access Policy Articles, as set forth at http:// nrs.harvard.edu/urn-3:HUL.InstRepos:dash.current.terms-of-use\#OAP

\section{Share Your Story}

The Harvard community has made this article openly available.

Please share how this access benefits you. Submit a story.

Accessibility 
Running head: RANDOMNESS AND FREE WILL

Characters: 25,340

\author{
Mistaking Randomness for Free Will \\ Jeffrey P. Ebert ${ }^{*}$ and Daniel M. Wegner \\ Department of Psychology, Harvard University, 33 Kirkland St, Cambridge, Massachusetts \\ 02138, USA
}

In press at Consciousness and Cognition

* Corresponding author.

E-mail address: jebert@wjh.harvard.edu (J. P. Ebert). 


\begin{abstract}
Belief in free will is widespread. The present research considered one reason why people may believe that actions are freely chosen rather than determined: they attribute randomness in behavior to free will. Experiment 1 found that participants who were prompted to perform a random sequence of actions experienced their behavior as more freely chosen than those who were prompted to perform a deterministic sequence. Likewise, Experiment 2 found that, all else equal, the behavior of animated agents was perceived to be more freely chosen if it consisted of a random sequence of actions than if it consisted of a deterministic sequence; this was true even when the degree of randomness in agents' behavior was largely a product of their environments. Together, these findings suggest that randomness in behavior-one's own or another's - can be mistaken for free will.
\end{abstract}

Characters: 865

Keywords: free will; determinism; randomness; illusion of conscious will; choice; control; animacy; mind perception 


\section{Introduction}

This notion of alternative possibility, [determinists] say, this admission that any one of several things may come to pass, is, after all, only a roundabout name for chance; and chance is something the notion of which no sane mind can for an instant tolerate in the world.

—William James, The Dilemma of Determinism (1896)

In making his case for free will, James (1896) first had to convince a skeptical audience that it was sensible to believe in an indeterministic universe-one in which the future is not preordained, but instead open to several possibilities. Since James' time, belief in indeterminism has gained respectability, bolstered by discoveries in quantum mechanics that, according to some interpretations (e.g., Bohr, 1925), show that the universe is fundamentally indeterministic at smaller scales. Indeed, several proponents of free will have embraced quantum indeterminacy, arguing that random processes in the brain make freedom possible (Compton, 1931; Kane, 1996; Margenau, 1968; Popper \& Eccles, 1977).

Regardless of the merits of these arguments - and there are reasons to doubt that random processes can produce the kind of free will some may want them to (Dennett, 1984)their appeal may offer a clue as to why most people believe that humans have free will (Sarkissian et al., 2010). When the question is posed in abstract terms, the overwhelming majority of lay individuals say that free will is incompatible with a fully deterministic universe (Nichols \& Knobe, 2007), which suggests that belief in free will depends to some extent on the appearance of indeterminacy. We take this observation a step further and propose that evidence of behavioral indeterminacy gives rise to the perception that actions are freely chosen-even when this indeterminacy stems from random processes that have nothing to do 
with free will. Two experiments tested the hypothesis that people interpret randomness in their own (Experiment 1) and others' (Experiment 2) behavior as owing to free will.

\section{Experiment 1: Experiencing one's own actions as free}

The near-universality of free will belief suggests that the mind operates in a way that encourages the inference that one's actions are freely chosen. To begin with, people are often unaware of the environmental and biological factors affecting their behavior (Bargh \& Ferguson, 2000; Nisbett \& Wilson, 1977). Instead, what they are usually aware of is intending to act prior to acting (Libet, Gleason, Wright, \& Pearl, 1983). According to the theory of apparent mental causation (Wegner, 2002; Wegner \& Wheatley, 1999), the constant conjunction between intention and action leads people to infer that their conscious will-and not invisible environmental and biological factors - is what causes their behavior.

This theory helps explain why people believe that they consciously choose how to actin other words, the will part of free will. Still, one can imagine a person who would experience willing actions without feeling that they were free. For instance, someone who precisely every minute has the intention "I'm going to wiggle my finger" and then does so should feel like he or she is willing the finger to move; however, the clockwork predictability of this behavior should undermine any feeling of free choice or sense that he or she could have acted otherwise. This example suggests that evidence of behavioral indeterminacy is important for the inference of free will. Because randomness is a kind of indeterminacy, people may mistakenly interpret randomness in behavior as owing to free will. The present experiment tested this intuition by prompting some participants to perform a deterministic sequence of actions and others a random sequence, and measuring how much free choice they experienced over their behavior. 


\subsection{Method}

\subsubsection{Participants}

Two hundred forty-nine individuals from the Harvard Study Pool (146 female, 103 male) completed this online experiment in exchange for course credit. ${ }^{1}$

\subsubsection{Procedure}

Participants were randomly assigned to one of four cells in a 2 (sequence: deterministic, random) $\times 2$ (preview: preview, no preview) between-participants design. All participants completed a series of 100 trials on which they responded to a prompt (either a ' $P$ ' or ' $Q$ ') to press a key. This prompt remained on the screen until the participant pressed either ' $P$ ' or ' $Q$,' at which point the screen went blank for $2 \mathrm{~s}$ until the next trial. In the deterministic condition, if the previous prompt was a ' $P$,' the next was a ' $Q$,' and vice versa. In the random condition, each prompt was selected randomly, with a 50\% chance of ' $\mathrm{P}$ ' rather than ' $\mathrm{Q}$.' In the preview condition, participants were given advance notice of the action they would be prompted to perform on that trial. For example, at the beginning of trials on which ' $\mathrm{P}$ ' was the prompt, the phrase "I'll press $\mathrm{P}$ " appeared for $1 \mathrm{~s}$, followed by a blank screen for $.5 \mathrm{~s}$, followed by the prompt. The preview was meant to help equalize the two sequence conditions with respect to the amount of action-relevant thought participants experienced prior to acting (Wegner \& Wheatley, 1999), as well as the difficulty of the keypress task. In the no preview condition, the trial began immediately with the prompt.

\footnotetext{
${ }^{1}$ As a precaution, nine participants were excluded for having either a median RT greater than $1000 \mathrm{~ms}$ or a proportion correct less than .90 on the keypress task, and 26 more for maximally inconsistent responses (rating a statement and its reverse-coded analogue both as 1 or both as 5) on the primary dependent measure. Including these participants did not change the significance of the main results.
} 
After these trials, participants completed the primary dependent measure, a four-item Likert scale $^{2}$ ( $\alpha=.75$; analysis confirmed a one-factor solution) assessing perceived choice during the keypress task ("I felt that I was FREELY CHOOSING which keys to press"; "I felt that I had NO CHOICE about which keys to press" [R]; "On any trial, I COULD HAVE PRESSED A DIFFERENT KEY THAN I DID”; “On any trial, which key I pressed was the UNAVOIDABLE PRODUCT OF PRIOR EVENTS" [R]). These items were designed to capture prominent definitions of free will from philosophy and psychology (Baumeister, 2008; James, 1896; Kane, 1996; Nichols \& Knobe, 2007; O'Connor, 2010; Wegner, 2002). Then, as a manipulation check, participants completed two Likert items $(\alpha=.92)$ concerning the perceived unpredictability of the keypress prompts ("Which keys I was told to press seemed RANDOM or UNPREDICTABLE"; "Which keys I was told to press seemed PATTERNED or PREDICTABLE" [R]).

To assess potential confounds, participants completed two Likert items ( $\alpha=.72$ ) concerning how boring they found the keypress task ("I found the keypress task to be INTERESTING and ENGAGING" [R]; "I found the keypress task to be BORING and TEDIOUS"); two items ( $\alpha=.59$ ) concerning how much they tried to control which prompts appeared ("I TRIED TO CONTROL which prompt—P or Q-would appear next"; "I SIMPLY WAITED to see which prompt-P or Q-would appear next" [R]); and two items $(\alpha=.65)$ concerning belief that they were able to control which prompts appeared ("I believe that I WAS ABLE TO CONTROL which prompts appeared"; "I believe that I HAD NO CONTROL over which prompts appeared" [R]). They also completed a state version of the 10-item International Positive and Negative Affect Schedule Short Form (I-PANAS-SF; Thompson, 2007). To assess potential moderators,

\footnotetext{
${ }^{2}$ In both experiments, Likert items were rated on 5-point scales and administered in the order described.
} 
participants completed the 28-item Free-will and Determinism (FAD; Paulhus \& Margesson, 2008) scale and two Likert items $(\alpha=.59)$ concerning whether humans have free will ("Human beings have free will"; "Human behavior is fully determined by causes other than free will" [R]) and indicated their sex, political orientation, and religious identification.

\subsection{Results}

The results for the deterministic and random conditions, split by preview condition, are shown in Table 1. Confirming the success of the sequence manipulation, perceived unpredictability of the prompts was greater in the random condition $(M=3.56, S D=1.16)$ than in the deterministic condition $(M=1.41, S D=0.85), F(1,210)=230.96, p<.000001, \eta_{p}^{2}=.52$. Perceived unpredictability did not differ between the preview and no preview conditions, $F(1$, $210)=0.18, n s$, and there was no evidence of a Sequence $\times$ Preview interaction, $F(1,210)=$ $0.01, n s$. As predicted, perceived choice was greater in the random condition $(M=3.81, S D=$ $0.87)$ than in the deterministic condition $(M=3.41, S D=1.02), F(1,210)=10.89, p=.001, \eta_{p}{ }^{2}=$ .05. This effect did not differ by preview condition, as revealed by a non-significant Sequence $x$ Preview interaction, $F(1,210)=0.50$, ns. Perceived choice was somewhat lower in the preview condition $(M=3.53, S D=1.02)$ than in the no preview condition $(M=3.69, S D=0.91)$, but this difference was not significant, $F(1,210)=2.79, p=.096, \eta_{p}{ }^{2}=.01$.

Might the effect of sequence condition on perceived choice have owed to some other difference between the two conditions? Among participants not given previews, it appears that the keypress task was more difficult in the random condition, as revealed by slower RTs and a lower proportion of correct responses compared to the deterministic condition (see Table 1). However, neither RT nor proportion correct was correlated with perceived choice in either the 
random or the deterministic conditions, all ps > .209, and neither variable differed by sequence condition among those who were given previews, which suggests that differences in task difficulty cannot explain the effect of sequence condition on perceived choice. Among participants given previews, positive affect was greater in the random condition than in the deterministic condition, and it was positively correlated with perceived choice, $r(57)=.26, p=$ .043 , in the random condition. However, in a one-way ANCOVA, positive affect was not a significant covariate, $F(1,99)=1.12, p=.293$, and the effect of sequence condition on perceived choice remained marginally significant, $F(1,99)=3.70, p=.057, \eta_{p}{ }^{2}=.04$. Even among those given previews, then, positive affect cannot explain the effect of sequence condition on perceived choice; instead, it may be that the greater positive affect experienced in the random condition resulted from participants' heightened perceived choice (Brehm, 1966; Deci \& Ryan, 1985).

To test whether participants' free will beliefs (the four subscales of the FAD scale, our two-item measure of whether humans have free will) and other characteristics (sex, political orientation, religious identification) predicted perceived choice, or whether these variables moderated the effect of sequence on perceived choice, a series of hierarchical regressions was conducted. In each regression, step 1 included sequence condition and the particular free will or demographic variable of interest; step 2 included the interaction of these two variables. None of the free will or demographic variables significantly predicted perceived choice, all $p s>$ .149 , and none interacted with sequence condition, all $p s>.134$.

\subsection{Discussion}


These results support the hypothesis that randomness in one's behavior contributes to the experience that one is freely choosing how to act. Actions performed in a random sequence were experienced as more freely chosen than actions performed in a deterministic sequenceeven though in both cases actions were prompted and therefore not free. This effect did not owe to potential confounds such as task difficulty or mood, and it was not moderated by participants' free will beliefs or other characteristics. That even determinists exhibited this effect suggests that it is difficult to turn off the experience of freely willing one's actions (Wegner, 2008).

\section{Experiment 2: Perceiving another's actions as free}

Experiment 2a sought further evidence that people attribute randomness to free will, this time focusing on the perceived freedom of others' behavior. To sidestep preconceptions about how much free will others possess, participants viewed the behavior of colored triangles, which they were asked to imagine were "aliens" on another planet. Previous research has used simple geometric shapes to investigate how motion cues give rise to the perception of animacy, intentionality, emotions, and personality (Gaur \& Scassellati, 2006; Gergely, Nádasdy, Csibra, \& Bíró, 1995; Heider \& Simmel, 1944; Scholl \& Tremoulet, 2000), but unexplored is the question of what gives rise to the perception that an agent is freely choosing its actions. Participants viewed aliens that behaved in ways that have been found to facilitate perceived animacy, with movement that was self-propelled (Premack, 1990), varied in speed and direction, and aligned with their principal axes (Tremoulet \& Feldman, 2000). To control for perceived intentionality, aliens did not pursue a visible goal. The prediction was that, all else equal, aliens behaving randomly would be seen as possessing more free will than those behaving deterministically. 
Of course, participants did not know that the behavior of both kinds of aliens stemmed from causes other than free will, and so it would not necessarily be a mistake if they ascribed greater free will to the more unpredictable kind. To help clarify the interpretation of our predicted results, a second experiment $(2 \mathrm{~b})$ was conducted that mirrored the design of $2 \mathrm{a}$, with one key difference: the behavior of each alien was visibly shaped by its environment. Specifically, participants were told that the aliens only traveled on flat terrain, which was depicted as a contiguous white region in the middle of a darker, textured background. In the videos, the aliens not only remained on the flat terrain, but they also visited every flat area at least once, meaning that participants saw at the outset everywhere the aliens would go. Because the behavior of both deterministic and random aliens was equally shaped by their environments, the latter were no more freely choosing their actions than the former. We predicted that random aliens would nevertheless be perceived as having more free will over their actions.

\subsection{Method}

\subsubsection{Participants}

Participants were recruited for an online study through Amazon's Mechanical Turk website. Participation was restricted to those located in the United States who had an approval rate greater than or equal to 95\%. Two hundred ninety-nine participants (165 female, 134 male) completed Experiment $2 a$ in exchange for $\$ 0.15$, and 103 (62 female, 41 male) completed Experiment $2 b$ in exchange for $\$ 0.20 .^{3}$

\footnotetext{
${ }^{3}$ As a precaution, 15 participants in Experiment 2a were excluded for having a completion time in the top or bottom $2.5 \%$, and 13 more for maximally inconsistent responses on the primary dependent measure. Following
} 


\subsubsection{Procedure}

Participants were randomly assigned to either a deterministic or random sequence condition, which refers to the behavior of the alien they viewed and rated first. All participants were asked to imagine that scientists had discovered alien life on another planet, and to watch videos of two distinct alien species - one blue, one green - knowing that they would be asked to give their impressions of each alien's behavior. In Experiment 2b, participants were also told that the aliens only traveled on flat terrain, which would appear white in the videos.

Each video began with an aerial view of a triangular alien $(13 \times 9$ pixels) facing north in the center of a textured background ( $625 \times 625$ pixels). In Experiment $2 b$, this rougher "terrain" was broken up by a path composed of overlapping white squares ( $15 \times 15$ pixels) in exactly those areas that the alien would visit. After remaining stationary for $0.5 \mathrm{~s}$, the alien performed seven sequences of nine actions in the following proportions: three forward moves; two left turns; two right turns; two rests. Forward moves consisted of a 13-pixel displacement in whatever direction the alien was facing. Turns consisted of a $90^{\circ}$ rotation without displacement. Each action was performed smoothly (24 fps) over the course of $0.5 \mathrm{~s}$, and was followed immediately by the next action. Deterministic aliens performed the same nine-action sequence seven times (for each participant, a different nine-action sequence was selected at random). Random aliens performed a different, randomly-shuffled nine-action sequence each time. Animations were programmed in ActionScript 3.0 with Adobe Flash CS4 Professional and are available online at www.wjh.harvard.edu/ jebert/AlienStim.htm. 
After viewing each video, participants completed the primary dependent measure, a 10item Likert scale ${ }^{4}(2 \mathrm{a}: \alpha=.94 ; 2 \mathrm{~b}: \alpha=.91$ ) assessing how much free choice they perceived the alien to have ("The alien was FREELY CHOOSING how to behave"; "The alien had NO CHOICE about how it behaved" [R]; "For any action the alien performed, it COULD HAVE ACTED DIFFERENTLY if it wanted to"; "Each action the alien performed was the UNAVOIDABLE PRODUCT OF PRIOR EVENTS" [R]; "The alien was CONSCIOUSLY DECIDING how to act"; "The alien was acting on AUTOPILOT" [R]; "The alien seemed to have FREE WILL"; "The alien's behavior seemed FULLY DETERMINED by causes other than free will" [R]; "The alien would be RESPONSIBLE if its behavior harmed somebody"; "The alien CAN'T HELP DOING WHAT IT DOES and shouldn't be punished if its behavior harmed somebody" [R]). They also rated Likert items concerning how alive, conscious, thoughtful about its behavior, intentional, purposeful, intelligent, friendly, competent, possessing of a soul, human, and similar to themselves the alien seemed, as well as a four-item (2a: $\alpha=.94 ; 2 \mathrm{~b}: \alpha=.95$ ) manipulation check on the perceived unpredictability of the alien's behavior ("The alien's actions were PREDICTABLE" [R]; "The alien's actions were UNPREDICTABLE"; "I noticed a PATTERN to the alien's behavior" [R]; "I did NOT notice any pattern to the alien's behavior"). Participants in Experiment $2 \mathrm{~b}$ completed an additional two-item $(\alpha=.78)$ check on their understanding that the alien's movement was constrained by the terrain ("The alien was only able to travel on flat (white) terrain"; "The alien could have traveled anywhere, including the rougher terrain" [R]). After rating the second alien,

\footnotetext{
${ }^{4}$ Analysis confirmed a one-factor solution for Experiment 2a; however, two factors emerged for Experiment 2b, with the two items pertaining to moral responsibility loading on the second factor. Given that these two items also loaded on the first factor in $2 \mathrm{~b}$, and in the interest of consistency, for both experiments all 10 items were averaged to create the perceived choice variable.
} 
participants completed the FAD scale and our two-item measure of free will belief, and then indicated their sex, political orientation, and religious identification.

\subsection{Results}

For both experiments, the between-participants results for the deterministic and random conditions are shown in Table 2.

\subsubsection{Experiment $2 a$}

Confirming the success of the sequence manipulation, perceived unpredictability was greater for the random alien $(M=3.02, S D=1.15)$ than for the deterministic alien $(M=1.75, S D$ $=0.90), F(1,269)=103.01, p<.000001, \eta_{p}^{2}=.28$. As predicted, perceived choice was greater for the random alien $(M=3.36, S D=0.85)$ than for the deterministic alien $(M=2.76, S D=0.82)$, $F(1,269)=34.38, p<.000001, \eta_{p}^{2}=.11$. The random alien was also perceived to be more thoughtful about its behavior than the deterministic alien, but otherwise there were no significant differences in how the two were perceived (see Table 2).

To test whether participants' free will beliefs and other characteristics predicted perceived choice or moderated the effect of sequence on perceived choice, a series of hierarchical regressions was conducted as in Section 2.2. The free will subscale of the FAD scale significantly predicted perceived choice, $\beta=.19, t(268)=3.36, p=.001$; likewise, our two-item measure of free will belief marginally predicted perceived choice, $\beta=.11, t(268)=1.85, p=.065$

and significantly interacted with sequence condition, $F(1,267)=10.18, p=.002, R_{\text {change }}{ }^{2}=.03$, indicating that free will believers were more likely than non-believers to see both kinds of aliens, but especially the random one, as behaving freely. No other variable significantly predicted perceived choice, all ps $>.085$, or interacted with sequence condition, all $p s>.132$. 


\subsubsection{Experiment $2 b$}

Once again, perceived unpredictability was greater for the random alien $(M=2.72, S D=$ 1.12) than for the deterministic alien $(M=1.28, S D=0.46), F(1,89)=62.52, p<.000001, \eta_{p}^{2}=$ .41. In addition, participants in the random $(M=4.15, S D=0.81)$ and deterministic $(M=4.38$, $S D=0.82$ ) conditions understood equally well that the alien's movement was constrained by its environment, $F(1,89)=1.77, p=.187$. As predicted, perceived choice was greater for the random alien $(M=3.26, S D=0.79)$ than for the deterministic alien $(M=2.67, S D=0.76), F(1$, $89)=13.28, p<.001, \eta_{p}{ }^{2}=.13$. The random alien was also perceived to be more conscious, thoughtful about its behavior, possessing of a soul, and human than the deterministic alien, but otherwise there were no significant differences in how the two were perceived (see Table 2). Participants' free will beliefs and other characteristics were not found to significantly predict perceived choice, all $p s>.246$, or moderate the effect of sequence on perceived choice, all $p s>$ .074 .

\subsection{Discussion}

These results support the hypothesis that randomness in others' behavior contributes to the perception that they are freely choosing how to act. The actions of randomly behaving agents were seen as more freely chosen than those of deterministically behaving agents, even though the former were not perceived to be any more alive, intentional, or competent. This difference in perceived choice obtained even when the behavior of both kinds of agents was largely a product of their environments (and thus not free will). Given the procedural differences between Experiments 1 and 2, as well as inherent asymmetries between performing actions and watching others do so (Blakemore, Wolpert, \& Frith, 2000), the fact that 
both experiments found evidence of behavioral randomness being attributed to free will strengthens the conclusion that this is a general phenomenon.

\section{General discussion}

The present results demonstrate that, under certain circumstances, people interpret randomness in their own and others' behavior as owing to free choice-that people mistake randomness for free will. This confusion is understandable: Free will, as understood by incompatibilists such as James (1896), requires indeterminacy; though the converse is not true-for example, equipping the brain with a random choice-making module would not meet most definitions of free will-some may nevertheless construe any evidence of behavioral indeterminacy as evidence of free will. And, in a narrow sense, it is true that a person could have acted otherwise if his or her behavior was yoked to the outcome of a random process, such as a coin flip-not because the person could have freely willed the alternative action, but because the coin could have just as easily landed tails.

Some caveats are in order. First, the present results, with their modest effect sizes, do not establish that behavioral randomness is necessary or sufficient for actions to be perceived as freely chosen-only that randomness can contribute to this perception. With regards to necessity, our view is that randomness has this effect because it provides clear evidence of indeterminacy; given that, at a certain level of complexity, deterministic behavior may seem just as indeterministic (Lorenz, 1972), it should be possible for wholly determined actions to appear freely chosen as well. With regards to sufficiency, we do not wish to imply that any random action will do; at a minimum, the action must make sense within the context in which it is performed. For this reason, care was taken in the present research to create situations in 
which random behavior seemed just as rational, intentional, and competent as deterministic behavior. We maintain that in the real world, too, randomness can give the impression of free will, provided that the resulting behavior is broadly consistent with the individual's goals, or can at least be interpreted thus after the fact (Gazzaniga, 1983; Gilovich, 1991). Importantly, this condition is met whenever a person chooses between two similarly desirable options.

Finally, the present research says little about whether humans actually do have free will, and it is silent on whether free will belief is beneficial (Baumeister, Masicampo, \& DeWall, 2009; Vohs \& Schooler, 2008) or costly (Ebert \& Wegner, submitted for publication). Nevertheless, our findings may help to explain where this important belief comes from.

\section{Acknowledgments}

This research was supported in part by NSF Grant BCS-0841746. We thank Lisa Stewart for programming assistance and Joe Paxton for helpful comments.

\section{References}

Bargh, J. A. \& Ferguson, M. J. (2000). Beyond behaviorism: The automaticity of higher mental processes. Psychological Bulletin, 126, 925-945.

Baumeister, R. F. (2008). Free will in scientific psychology. Perspectives on Psychological Science, 3, 14-19.

Baumeister, R. F., Masicampo, E. J., \& DeWall, C. N. (2009). Prosocial benefits of feeling free:

Disbelief in free will increases aggression and reduces helpfulness. Personality and Social Psychology Bulletin, 35, 260-268.

Blakemore, S. J., Wolpert, D., \& Frith, C. (2000). Why can't you tickle yourself? NeuroReport, 11, 11-15. 
Bohr, N. (1925). Atomic theory and mechanics. Nature, 116, 845-852.

Brehm, J. W. (1966). A theory of psychological reactance. New York: Academic Press.

Compton, A. H. (1931). The uncertainty principle and free will, Nature, 74, 172.

Deci, E., \& Ryan, R. (1985). Intrinsic motivation and self-determination in human behavior. New York: Plenum.

Dennett, D. C. (1984). Elbow room: The varieties of free will worth wanting. Cambridge, MA: MIT Press.

Ebert, J. P., \& Wegner, D. M. (submitted for publication). How free are free will believers? Belief is associated with underestimating one's susceptibility to influence.

Gaur, V., \& Scassellati, B. (2006). Which motion features induce the perception of animacy? In International Conference for Developmental Learning, Bloomington, Indiana.

Gazzaniga, M. S. (1983). Right hemisphere language following brain bisection: A 20-year perspective. American Psychologist, 38, 525-537.

Gergely, G., Nádasdy, Z, Csibra, S., \& Bíró, S. (1995). Taking the intentional stance at 12 months of age, Cognition, 56, 165-193.

Gilovich, T. (1991). How we know what isn't so: The fallibility of human reason in everyday life. New York: Free Press.

Heider, F. \& Simmel, M. (1944). An experimental study of apparent behavior. The American Journal of Psychology, 57, 243-259.

James, W. (1896). The will to believe: and other essays in popular philosophy. New York: Longmans Green and Co.

Kane, R. (1996). The significance of free will. New York: Oxford University Press. 
Libet, B., Gleason, C. A., Wright, E. W., \& Pearl, D. K. (1983). Time of conscious intention to act in relation to onset of cerebral activity (readiness-potential): the unconscious initiation of a freely voluntary act. Brain, 106, 623-642.

Lorenz, E. (1972). Predictability: Does the flap of a butterfly's wings in Brazil set off a Tornado in Texas? Presented at the American Association for the Advancement of Science, Washington, D.C.

Margenau, H. (1968). Scientific indeterminism and human freedom. Latrobe, PA: Archabbey Press.

Nichols, S., \& Knobe, J. (2007). Moral responsibility and determinism: The cognitive science of folk intuitions. Nous, 41, 663-685.

Nisbett, R., \& Wilson, T. (1977). Telling more than we can know: Verbal reports on mental processes. Psychological Review, 84, 231-259.

O'Connor, T. (2010). Free will. In E. N. Zalta (Ed.), The Stanford Encyclopedia of Philosophy (Winter 2010 Edition). <http://plato.stanford.edu/archives/win2010/entries/freewill/>.

Paulhus, D. L., \& Margesson, A. (2008). Free-will and Determinism (FAD) scale. Unpublished measure, University of British Columbia, Vancouver.

Popper, K., \& Eccles, J. C. (1977). The self and its brain: an argument for interactionism. New York: Springer-Verlag.

Premack, D. (1990). The infant's theory of self-propelled objects. Cognition, 36, 1-16.

Sarkissian, H., Chatterjee, A., De Brigard, F., Knobe, J., Nichols, S., \& Sirker, S. (2010). Is belief in free will a cultural universal? Mind \& Language, 25, 346-358. 
Scholl, B. J., \& Tremoulet, P. D. (2000). Perceptual causality and animacy. Trends in Cognitive Sciences, 4, 299-309.

Tremoulet, P. D., \& Feldman, J. (2000). Perception of animacy from the motion of a single object. Perception, 29, 943-951.

Thompson, E. R. (2007). Development and validation of an internationally reliable short-form of the positive and negative affect schedule (PANAS). Journal of Cross-Cultural Psychology, $38,227-242$.

Vohs, K. D., \& Schooler, J. W. (2008). The value of believing in free will: encouraging a belief in determinism increases cheating. Psychological Science, 19, 49-54.

Wegner, D. M. (2002). The illusion of conscious will. Cambridge, MA: MIT Press.

Wegner, D. M. (2008). Self is magic. In J. Baer, J. C. Kaufman, \& R. F. Baumeister (Eds.), Are we free? Psychology and free will (pp. 226-247). New York: Oxford University Press.

Wegner, D. M., \& Wheatley, T. P. (1999). Apparent mental causation: Sources of the experience of will. American Psychologist, 54, 480-492. 
Table 1

Means and Standard Deviations for the Deterministic and Random Conditions, Split by Preview Condition, in Experiment 1

\begin{tabular}{|c|c|c|c|c|c|c|}
\hline & \multicolumn{3}{|c|}{ No Preview } & \multicolumn{3}{|c|}{ Preview } \\
\hline & \multirow{2}{*}{$\begin{array}{l}\text { Deterministic } \\
M(S D)\end{array}$} & \multirow{2}{*}{$\begin{array}{l}\text { Random } \\
-M(S D)\end{array}$} & \multirow[b]{2}{*}{$p$} & \multirow{2}{*}{$\begin{array}{l}\text { Deterministic } \\
-M(S D)\end{array}$} & \multirow{2}{*}{$\begin{array}{l}\text { Random } \\
-M(S D)\end{array}$} & \multirow[b]{2}{*}{$p$} \\
\hline & & & & & & \\
\hline Perceived choice & $3.51(0.98)$ & $3.91(0.78)$ & .019 & $3.26(1.08)$ & $3.72(0.93)$ & .024 \\
\hline Freely choosing & $3.25(1.36)$ & $3.71(1.18)$ & .059 & $2.99(1.28)$ & $3.30(1.46)$ & .270 \\
\hline Acted otherwise & $3.77(0.92)$ & $4.11(0.77)$ & .039 & $3.53(1.08)$ & $4.14(0.85)$ & .002 \\
\hline Perceived unpredictability & $1.43(0.85)$ & $3.60(1.12)$ & .000 & $1.38(0.87)$ & $3.53(1.20)$ & .000 \\
\hline \multicolumn{7}{|l|}{ Potential confounds } \\
\hline Found task boring & $4.58(0.83)$ & $4.37(0.91)$ & .189 & $4.77(0.50)$ & $4.57(0.78)$ & .145 \\
\hline Tried to control prompts & $2.00(0.91)$ & $1.82(0.95)$ & .299 & $1.99(1.14)$ & $1.69(0.99)$ & .157 \\
\hline Felt control over prompts & $1.53(0.76)$ & $1.41(0.67)$ & .413 & $1.34(0.59)$ & $1.53(0.80)$ & .174 \\
\hline Positive affect & $2.51(0.82)$ & $2.63(0.69)$ & .406 & $2.17(0.84)$ & $2.65(0.87)$ & .006 \\
\hline Negative affect & $1.75(0.66)$ & $1.80(0.69)$ & .678 & $1.88(0.69)$ & $1.70(0.62)$ & .163 \\
\hline Median RT (ms) & $372(90)$ & $470(61)$ & .000 & $357(87)$ & $343(86)$ & .439 \\
\hline Proportion correct & $.990(.012)$ & $.973(.019)$ & .000 & $.996(.010)$ & .994 (.009) & .287 \\
\hline
\end{tabular}

Note. The two components of perceived choice, as well as perceived unpredictability and the first three potential confounds, are each averages of a pair of items, one of which was reverse-coded. Median RT and proportion correct are for the keypress task. Each $p$ comes from an ANOVA and indicates the significance of sequence condition within that particular preview condition. 
Table 2

Means and Standard Deviations for the Deterministic and Random Conditions in Experiments 2a and 2b

\begin{tabular}{|c|c|c|c|c|c|c|}
\hline & \multicolumn{3}{|c|}{ Experiment $2 \mathrm{a}$} & \multicolumn{3}{|c|}{ Experiment $2 b$} \\
\hline & \multirow{2}{*}{$\begin{array}{l}\text { Deterministic } \\
M(S D)\end{array}$} & \multirow{2}{*}{$\begin{array}{l}\text { Random } \\
\text { M }(S D)\end{array}$} & \multirow[b]{2}{*}{$p$} & \multirow{2}{*}{$\begin{array}{l}\text { Deterministic } \\
-M(S D)\end{array}$} & \multirow{2}{*}{$\begin{array}{l}\text { Random } \\
-M(S D)\end{array}$} & \multirow[b]{2}{*}{$p$} \\
\hline & & & & & & \\
\hline Perceived choice & $2.76(0.82)$ & $3.36(0.85)$ & .000 & $2.67(0.76)$ & $3.26(0.79)$ & .000 \\
\hline Freely choosing & $2.84(1.04)$ & $3.46(1.04)$ & .000 & $2.66(1.02)$ & $3.42(0.98)$ & .001 \\
\hline Acted otherwise & $2.98(0.87)$ & $3.52(0.93)$ & .000 & $2.89(1.00)$ & $3.42(0.92)$ & .010 \\
\hline Consciously deciding & $2.53(0.95)$ & $3.25(0.89)$ & .000 & $2.33(0.89)$ & $3.25(0.98)$ & .000 \\
\hline Free will & $2.64(1.02)$ & $3.32(1.01)$ & .000 & $2.48(0.91)$ & $3.20(1.01)$ & .001 \\
\hline Responsible & $2.82(0.92)$ & $3.24(1.00)$ & .000 & $3.00(1.06)$ & $3.03(0.84)$ & .873 \\
\hline \multicolumn{7}{|l|}{ Other characteristics } \\
\hline Alive & $3.47(1.25)$ & $3.60(1.24)$ & .396 & $3.23(1.40)$ & 3.68 (1.09) & .086 \\
\hline Conscious & $3.14(1.23)$ & $3.33(1.12)$ & .185 & $2.95(1.22)$ & $3.47(1.02)$ & .031 \\
\hline Thoughtful & 2.70 (1.09) & $3.21(1.12)$ & .000 & $2.45(1.17)$ & $3.36(1.17)$ & .000 \\
\hline Intentional & $3.04(1.18)$ & $3.26(1.09)$ & .100 & $2.89(1.26)$ & $3.30(1.12)$ & .103 \\
\hline Purposeful & $3.01(1.17)$ & $2.81(1.18)$ & .150 & $3.36(1.22)$ & $3.26(1.24)$ & .676 \\
\hline Intelligent & $2.56(0.97)$ & $2.71(0.98)$ & .227 & $2.41(1.15)$ & $2.87(1.14)$ & .056 \\
\hline Friendly & $2.73(0.74)$ & $2.85(0.73)$ & .180 & $2.61(0.78)$ & $2.81(0.68)$ & .208 \\
\hline Competent & $2.77(0.88)$ & $2.86(0.91)$ & .410 & $2.75(1.06)$ & $2.83(0.89)$ & .698 \\
\hline Soul-having & $2.32(0.93)$ & $2.38(0.91)$ & .613 & $2.05(0.94)$ & $2.45(0.86)$ & .036 \\
\hline Human & $1.93(0.90)$ & $2.05(0.98)$ & .273 & $1.70(0.80)$ & $2.23(1.01)$ & .007 \\
\hline Similar to you & $1.75(0.86)$ & $1.78(0.92)$ & .773 & $1.52(0.76)$ & $1.83(0.96)$ & .097 \\
\hline Perceived unpredictability & $1.75(0.90)$ & $3.02(1.15)$ & .000 & $1.28(0.46)$ & $2.72(1.12)$ & .000 \\
\hline
\end{tabular}


Unpredictable

$1.82(0.95)$

$1.68(1.02)$

$3.16(1.15)$

2.89 (1.31)

.000

$1.34(0.59)$

$2.87(1.27)$

$2.56(1.15)$

.000

Unpatterned

Note. The five components of perceived choice and the two components of perceived unpredictability are each averages of a pair of items, one of which was reverse-coded. Each $p$ comes from an ANOVA and indicates the significance of sequence condition. 